\title{
Influence of Ag doping on Optical Properties of Nanocrystalline Titanium Dioxide prepared by PLD
}

\author{
Ali A. Yousif*,Kadhim A. Aadim ${ }^{* *}$ and Nassar A. Hamzah* \\ *Department of Physics, College of Education, University of Al-Mustansiriyah, Baghdad, Iraq \\ **University of Baghdad, Department of Physics, Collage of Science, Iraq
}

\begin{abstract}
In this work, Silver Ag doped nanocrystalline titanium dioxide $\mathrm{TiO}_{2}$ films deposited with different concentration of $(\mathrm{TiO2})_{1-x}(\mathrm{Ag})_{x}$ of $x=(0,0.01,0.02,0.03,0.04$ and 0.05$)$ Wt. on glass substrates were prepared by pulsed laser deposition (PLD) method, using pulsed Nd-YAG laser with wavelength $(\lambda=1064 \mathrm{~nm})$ and duration (9ns) and energy $(700 \mathrm{~mJ})$.The research has been including the study of optical properties through measuring the specters of absorbance and transmittance of the wavelength range (320-1100)nm. The results have been showed that the films have high transmittance for all films around $60-94 \%$ in the visible region and NIR of the spectrum that we can use them as optical windows in solar cells.The results of has been showed the absorption coefficient the direct transition are controlled, The values of the energy gap are calculated of the allowed direct electronic transitions are (3.81-3.63)eV. The energy gap is decreased gradually whenever the impurities rate increases.
\end{abstract}

Keywords: optical properties, silver, titanium dioxide films, PLD.

\section{Introduction}

Titanium dioxide $\left(\mathrm{TiO}_{2}\right)$ has become one of the most researched semiconductor materials due to the great promise it has shown in the photocatalytic oxidation of organic minerals [1-3]. The basic mechanism is the creation of an electron-hole pair by exciting an electron from the valence to the conduction band through light absorption that exceeds the band gap energy [4-5].

Among the numerous oxide materials, titanium dioxide $\left(\mathrm{TiO}_{2}\right)$ has received unprecedented interest due to its superior physical, chemical properties, high stability and ability to be easily doped with active ions. This material was used for various optical applications such as high refractive index component of multilayer optical filter, gas sensors, antireflective coating, photocatalysts, and planar waveguides [6]. Due to a combination of such unique properties as high refractive index, high transmittance, chemical stability and photo-catalytic behavior, titanium dioxide constitutes a very valuable material for optical applications [7]. In recent years, many efforts have been directed toward shifting the optical sensitivity of the $\mathrm{TiO}_{2}$ from UV to the visible-light spectrum for the efficient use of solar radiation or artificial visible light [8]. It is generally agreed that the presence of metal or nonmetal dopants into $\mathrm{TiO}_{2}$ lattice increases the photocatalytic activity of the mater under visible light irradiation [9-12]. On the other side, producing porous $\mathrm{TiO}_{2}$ samples with large surface area can improve its photocatalytic properties by means of reducing the recombination rate of photo induced electronhole pairs. This is due to their faster arrival to the reaction site of the surface and efficient charge separation which increases the lifetime of the charge carriers and enhances the photocatalytic efficiency [13]. The aim of this work is to produce high-quality $\mathrm{Ag}$-dopedTiO $\mathrm{O}_{2}$ thin films for optical application by PLD. Special attention was paid to the influence of the processing parameters, such as dopant concentration into the targets on the optical properties of the films during the deposition.

\section{Experiment}

Ag-doped $\mathrm{TiO}_{2}$ thin films were synthesized by pulsed laser deposition system. Thin films were grown in a vacuum chamber generally in $\left(4 \times 10^{-2} \mathrm{mbar}\right)$ vacuum conditions. The Nd:YAG laser was operated at the wavelength of $(\lambda=1064 \mathrm{~nm})$ with the repetition rate of $(6 \mathrm{~Hz})$ and pulse duration of $(9 \mathrm{~ns})$. The target to substrate distance was $(2 \mathrm{~cm})$. Targets of pure $\mathrm{TiO}_{2}$ and $\mathrm{Ag}$-doped $\mathrm{TiO}_{2}$ films $\mathrm{x}=(0,0.01,0.02,0.03,0.04$ and $0.05)$ Wt. Thin films were grown in Oxygen environment with $\mathrm{O}_{2}$ partial pressure of $10^{-2}$ mbar at substrate temperature of $250 \mathrm{C}$. The absorption spectra of undoped and $\mathrm{Ag}$-dopedTiO ${ }_{2}$ thin films were studied by UVvisible-NIR (Perkin Elemer Company) spectrophotometer in spectral range of (320-1100) nm.

\section{Results and Discussion}

The optical Transmission spectra of the nanocrystalline $\mathrm{TiO}_{2}$ and $(\mathrm{TiO} 2)_{1-\mathrm{x}}(\mathrm{Ag})_{\mathrm{x}}$ films were measured in the region of $(320-1100 \mathrm{~nm})$ by using UV-VIS-NIR spectrometer at room temperature, fig.(1) shows the optical transmission spectra at various Ag contents for nanocrystalline $(\mathrm{TiO} 2)_{1-\mathrm{x}}(\mathrm{Ag})_{\mathrm{x}}$ films deposited on glass substrate. It is also found that the average transmittance of the $(\mathrm{TiO} 2)_{1-\mathrm{x}}(\mathrm{Ag})_{\mathrm{x}}$ films exceeded $94 \%$ at $\mathrm{x}=0$. This 
indicates that $\mathrm{TiO}_{2}$ film can be used as a window material in solar cells [14]. The transmission values of Ag NPs doped $\mathrm{TiO} 2$ thin films $(1 \%, 2 \%, 3 \%, 4 \%$ and $5 \%)$ are respectively. It is observed that the optical transmittance decreases with increasing the $\mathrm{Ag}$ contents this is consistent with the increase of the surface roughness promoting the increase of the surface scattering of the light. Both densification and agglomeration of the crystallites at the doping are responsible for this behavior. The lack of oscillations in the range of 320-1100 $\mathrm{nm}$ indicates that the samples are very thin, according to the results obtained by A. P. Caricatoa, et al[15].

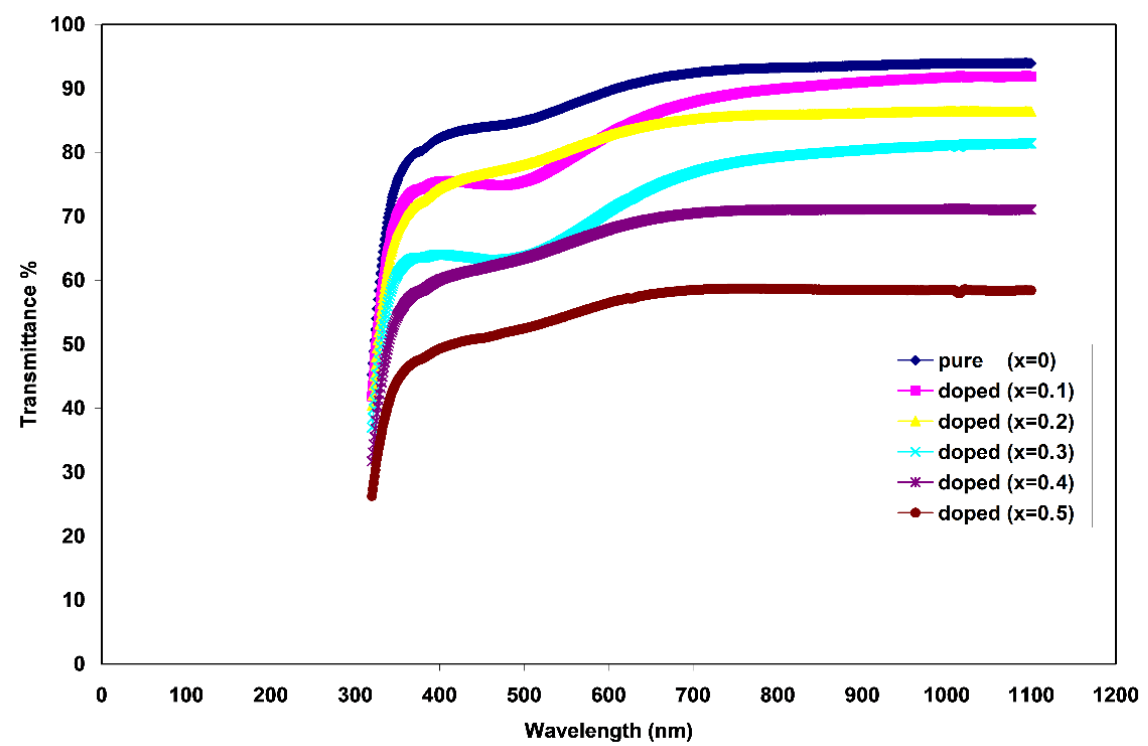

Figure (1): transmittance as a function of wavelength for $(\mathrm{TiO} 2)_{1-\mathrm{x}}(\mathrm{Ag})_{\mathrm{x}}$ films deposited on glass substrate with different Ag contents.

The optical absorbance spectra of the nanocrystalline $\mathrm{TiO}_{2}$ and $(\mathrm{TiO} 2)_{1-\mathrm{x}}(\mathrm{Ag})_{\mathrm{x}}$ thin films, as shown in fig. (2). It is clear that the absorption edge was shifted to visible region due to $\mathrm{Ag}$ doping. In other words, $\mathrm{Ag}$ doping causes decreasing in band gap energy, which is the minimum energy to promote the excited electron from valence band to conduction band. The more $\mathrm{Ag}$ content, the higher wavelength absorption. A similar trend was also observed in Lan Sun, et al.(2009) andHe, et al. (2002). Both studies concluded that the absorption edge shift possibly linked to the interaction of silver and $\mathrm{TiO}_{2}[16,17]$.

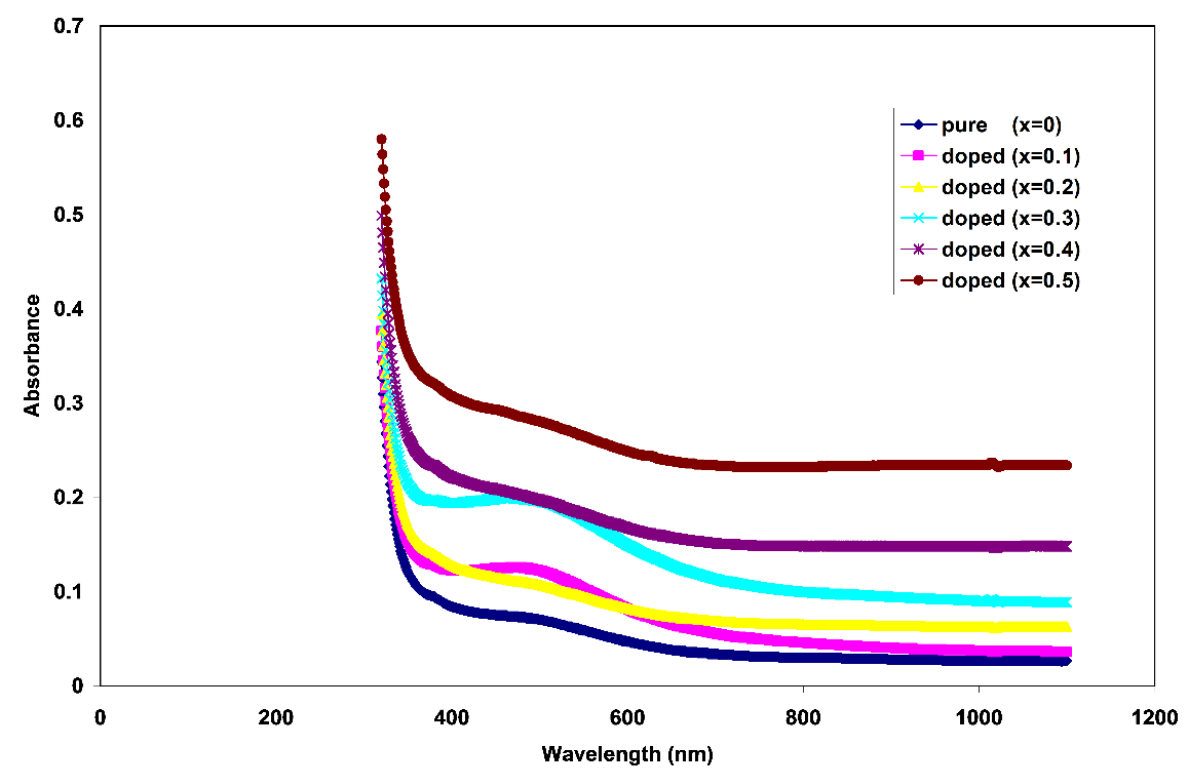

Fig. (2): absorbance spectra as a function of wavelength for $(\mathrm{TiO} 2)_{1-\mathrm{x}}(\mathrm{Ag})_{\mathrm{x}}$ films deposited on glass substrate with different $\mathrm{Ag}$ contents. 
Fig. (3) shows the absorption coefficient $(\alpha)$ as a function of photon energy of the $(\mathbf{T i O 2})_{1-\mathbf{x}}(\mathbf{A g})_{\mathbf{x}}$ thin films with different Ag-contents determined from absorbance measurements using equation (1). The absorption coefficient of (TiO2) $)_{1-\mathbf{x}}(\mathbf{A g})_{\mathbf{x}}$ thin films decreased sharply in the UV/VIS boundary, and then decreased gradually in the visible region because it is inversely proportional to the transmittance.[17].

$$
\alpha=2.303 \frac{A}{d}
$$

Where A is the absorption and (d) is the sample thickness.

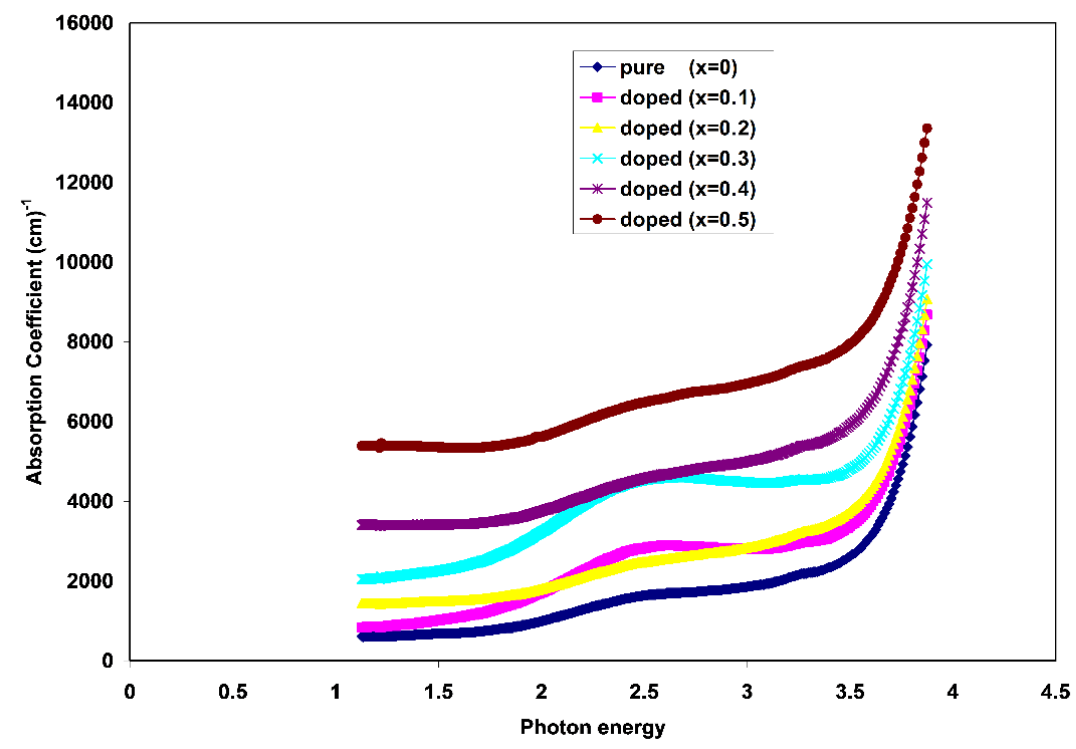

Figure (3): Absorption coefficient as a function of photon energy for $(\mathrm{TiO} 2)_{1-\mathrm{x}}(\mathrm{Ag})_{\mathrm{x}}$ films deposited on glass substrate with different Ag contents.

Fig. (4) Illustrates allowed direct transition electronic and the energy gap value depends on the films deposition conditions and its preparation method which influences in the crystalline structure .The variation in the structural properties and other variations is a reason for making variation in energy gap. Figures obtained for all the other thin films have a similar type of curve. The respective values of $\mathrm{E}_{\mathrm{g}}$ is obtained by extrapolation to $(\alpha h v)^{n}=0$. The $E_{g}$ values for direct band gap for all the thin films are summarized in table (1). It is found in literature that $(\mathbf{T i O 2})_{1-\mathbf{x}}(\mathbf{A g})_{\mathbf{x}}$ has a direct band gaps and the band gap values changes according to the preparation parameters and conditions.

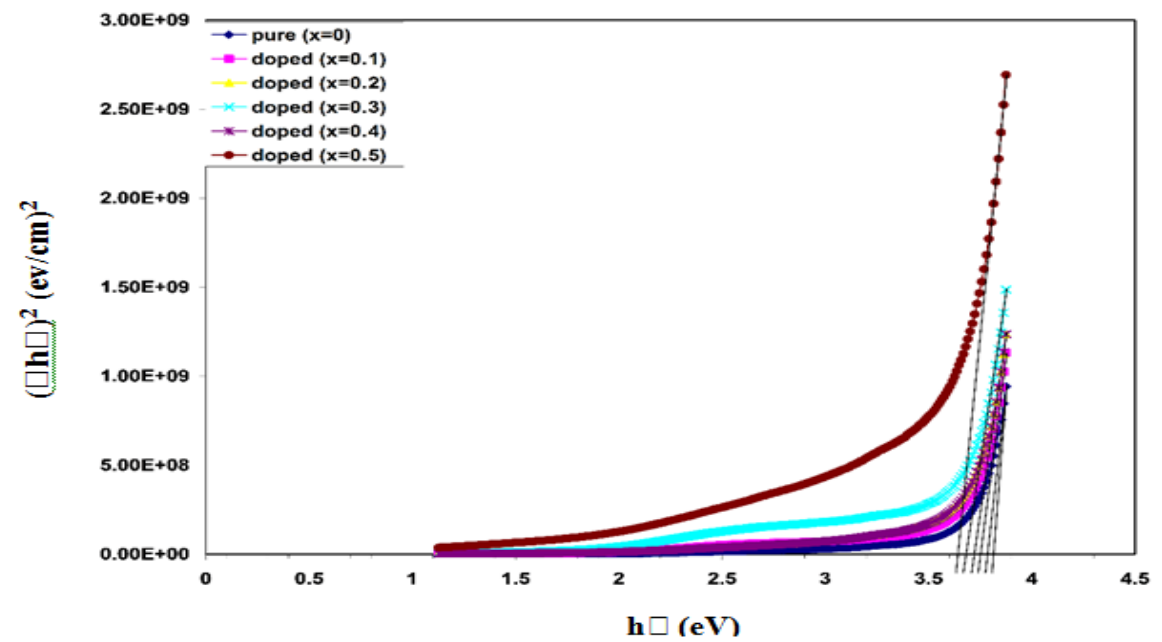

Fig. (4): Allowed direct electronic transitions of $(\mathrm{TiO} 2)_{1-\mathrm{x}}(\mathrm{Ag})_{\mathrm{x}}$ films deposited on glass substrate with different Ag contents. 
From table (1) and the following fig.(4), it can be observed that (Eg) is decreasing with the increasing of doping for all films. This result is consistent with previous researches [18].Ag doping led to increased levels of localized near valence band and conduction band and these levels ready to receive electrons and generate tails in the optical energy gap and tails is working toward reducing the energy gap, or can be attributed decrease energy gap to the increased size of particles in the films, this result corresponded to wavelength absorption analysis. Not only by reducing band gap energy, but the $\mathrm{Ag}$ doping was also able to prevent charge recombination between electron-hole pairs. [14]

Table (1): Shows allowed direct band gap and allowed indirect band gap for different doping of $(\mathrm{TiO} 2)_{1-\mathrm{x}}(\mathrm{Ag})_{\mathrm{x}}$ thin films

\begin{tabular}{|c|c|}
\hline Ag-content & Allowed direct band gap (eV) \\
\hline 0 & 3.81 \\
\hline 10 & 3.78 \\
\hline 20 & 3.75 \\
\hline 30 & 3.72 \\
\hline 40 & 3.68 \\
\hline 50 & 3.63 \\
\hline
\end{tabular}

Fig. (5) Shows the variation in refractive index of $(\mathbf{T i O 2})_{1-\mathbf{x}}(\mathbf{A g})_{\mathbf{x}}$ films with wavelength. The $(\mathbf{T i O 2})_{1-}$ ${ }_{x}(\mathbf{A g})_{x}$ films deposited on glass substrate at various $\mathrm{Ag}$ contents for $\mathrm{x}=0$ to $\mathrm{x}=0.05$. The values of the refractive index for the films at $\lambda=350 \mathrm{~nm}$ vary in the range from 1.90 to 2.64 as Ag-content increased from 0 to 0.05 as are summarized in table (2). In other words, the refractive indices of the $(\mathbf{T i O 2})_{\mathbf{1 - x}}(\mathbf{A g})_{\mathbf{x}}$ films are increasing with Mg-content increased as shown in fig.(5).

Table (2): Shows refractive index value for different doping of $(\mathrm{TiO} 2)_{1-\mathrm{x}}(\mathrm{Ag})_{\mathrm{x}}$ films.

\begin{tabular}{|c|c|}
\hline Ag-content & Refractive index \\
\hline 0 & 1.90 \\
\hline 0.01 & 2.13 \\
\hline 0.02 & 2.18 \\
\hline 0.03 & 2.39 \\
\hline 0.04 & 2.52 \\
\hline 0.05 & 2.64 \\
\hline
\end{tabular}

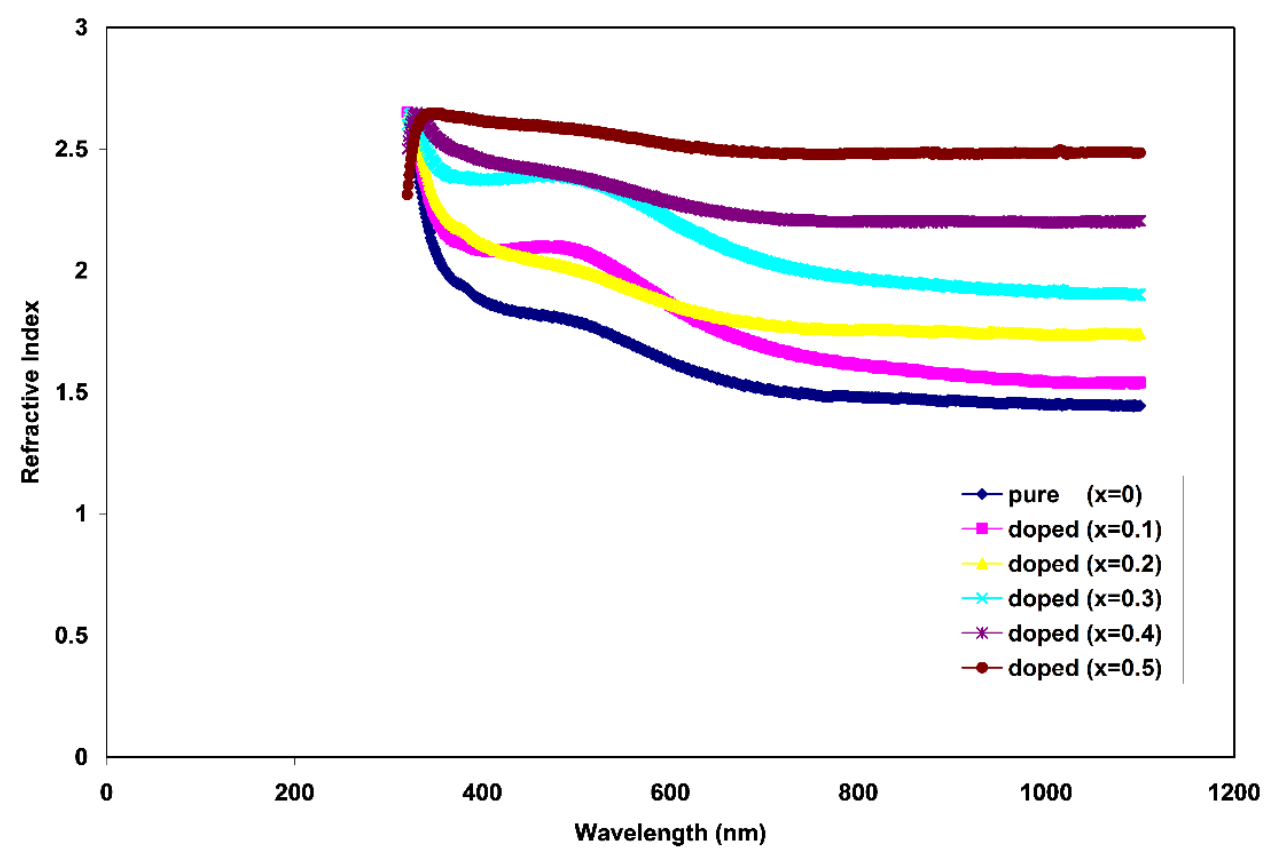

Fig. (5): Refractive index as a function of wavelength for $(\mathrm{TiO} 2)_{1-\mathrm{x}}(\mathrm{Ag})_{\mathrm{x}}$ films deposited on glass substrate with different Ag content. 
Fig. (6) Shows the variation in extinction coefficient of $(\mathbf{T i O 2})_{1-\mathbf{x}}(\mathbf{A g})_{\mathbf{x}}$ films with wavelength. It's clear from figure that the extinction coefficient has the same behavior absorption. The influence of doping $\mathrm{TiO}_{2} \mathrm{of} \mathrm{Ag}$ concentration on the extinction coefficient values, the increasing in the extinction coefficient values with increasing the doping concentration is due to increases in the absorption, this leads to decrease the defects or the tails deep so increases in the extinction coefficient values.

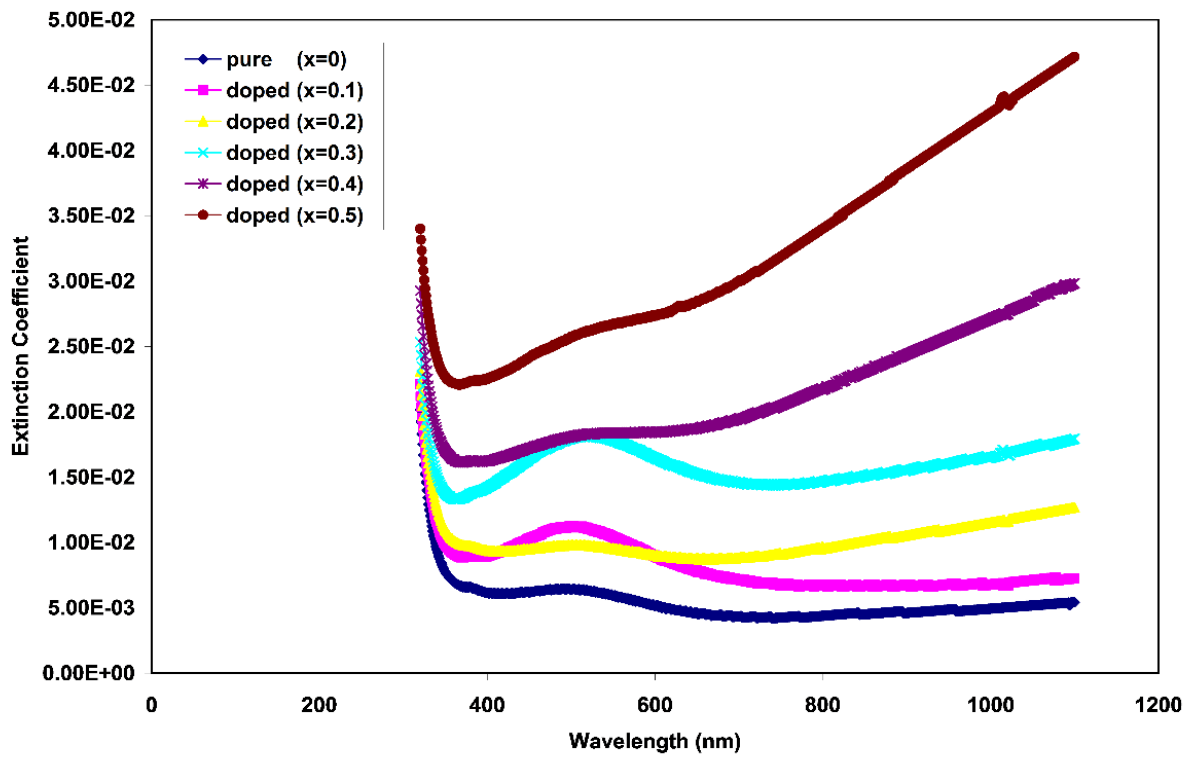

Fig. (6): extinction coefficient as a function of wavelength for $(\mathrm{TiO} 2)_{1-\mathrm{x}}(\mathrm{Ag})_{\mathrm{x}}$ films deposited on glass substrate with different Ag content.

The plots of real $\left(\varepsilon_{\mathrm{r}}\right.$ and $\left.\varepsilon_{\mathrm{i}}\right)$ parts of different $\mathrm{Ag}$ concentration for $\mathrm{TiO}_{2}$ films are illustrated in figures (7) and (8). Our values are comparatively good to those reported earlier [19-20]. The figures show that in all samples the real part behaves like the refractive index because of the smaller value of $\mathrm{K}^{2}$ compared to $\mathrm{n}^{2}$, while $\varepsilon_{2}$ depends mainly on the $\mathrm{K}$ values, which is related to the variation of the absorption coefficient, which means the real part and the imaginary part increases when $\mathrm{Ag}$ contents increases. Doping $\mathrm{TiO}_{2}$ with noble metal $\mathrm{Ag}$ will increase the real and the imaginary part of dielectric constants due to the increasing of the refractive index.

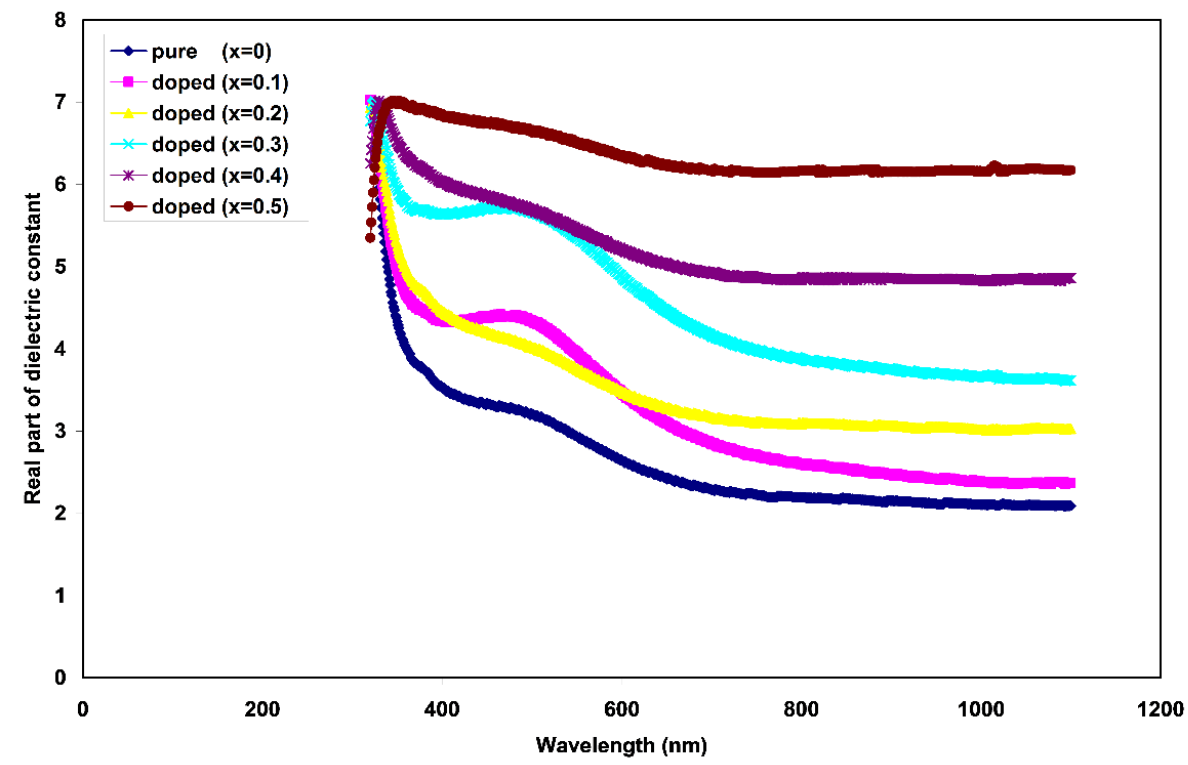

Fig. (7): Real $\left(\varepsilon_{\mathrm{r}}\right)$ parts of the dielectric function as a function of wavelength for $(\mathrm{TiO} 2)_{1-\mathrm{x}}(\mathrm{Ag})_{\mathrm{x}}$ films deposited on glass substrate with different Ag contents. 


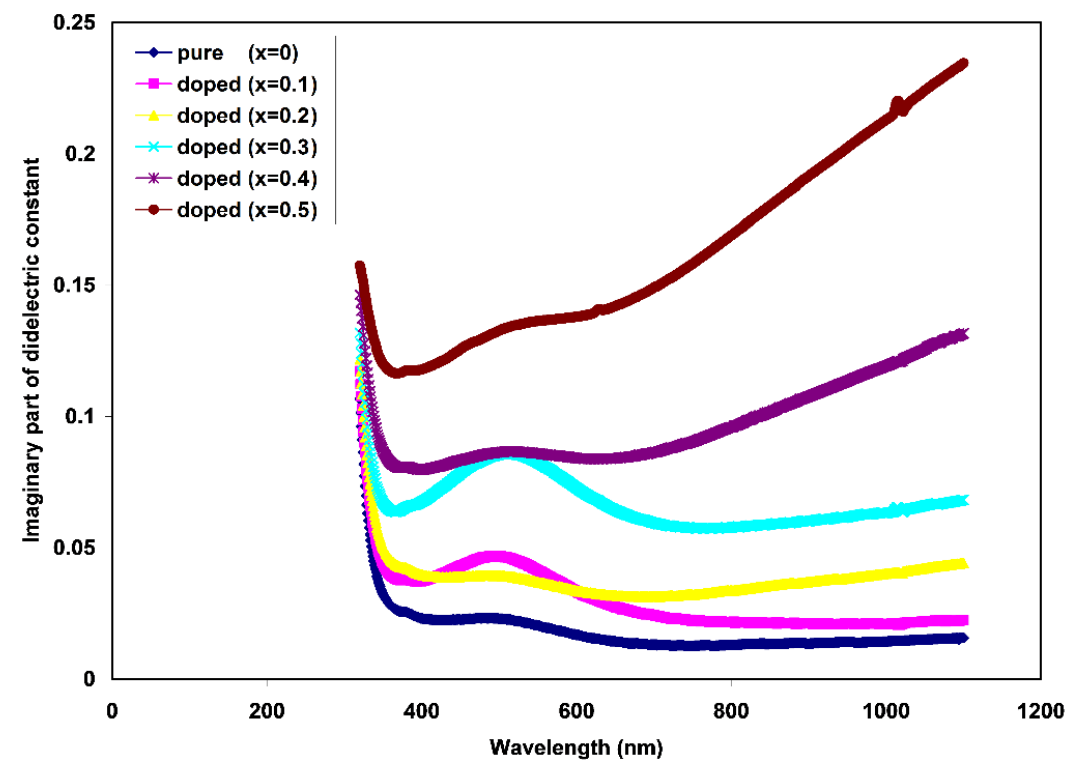

Fig. (8): Imaginary $\left(\varepsilon_{\mathrm{i}}\right)$ parts of the dielectric function as a function of wavelength for $(\mathrm{TiO} 2)_{1-\mathrm{x}}(\mathrm{Ag})_{\mathrm{x}}$ films deposited on glass substrate with different Ag content.

Fig. (9) Shows the variation of optical conductivity as a function of photon energy for different Ag-content of the (TiO2) $)_{1-\mathbf{x}}(\mathbf{A g})_{\mathbf{x}}$ films. The optical conductivity is calculated by using equation (2).

$$
\sigma=\frac{\alpha n c}{4 \pi . . . . . . . .(2)}
$$

Where (n) is the refractive index, and $(c)$ velocity of light in vacuum.

From Fig. (9), we can see that the optical conductivity increases with increasing photon energy and reaches a constant value. This suggests that the increase in optical conductivity is due to electron exited by photon energy, and the optical conductivity of the films increases with increasing Ag-contents in the films.

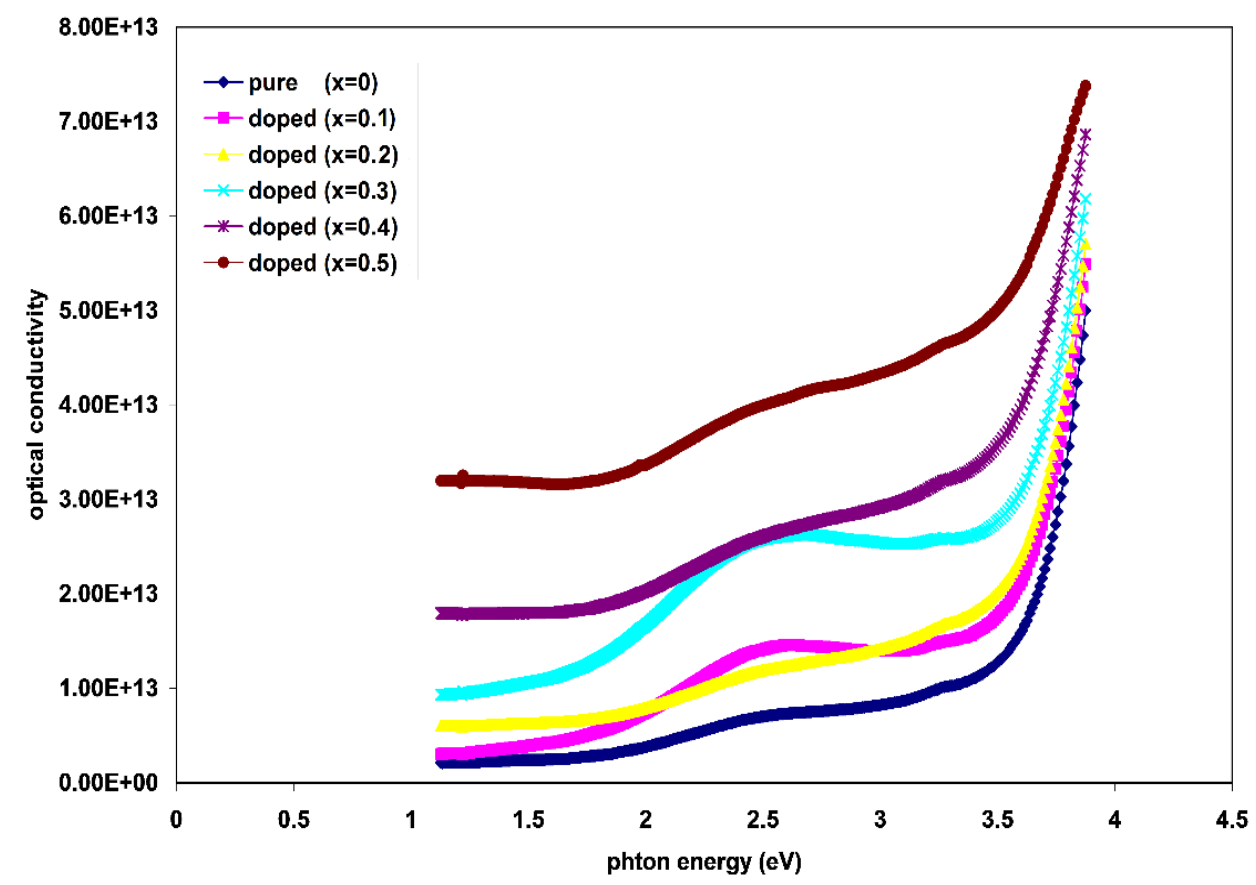

Fig. (9): Optical conductivity as a function of photon energy for $(\mathrm{TiO} 2)_{1-\mathrm{x}}(\mathrm{Ag})_{\mathrm{x}}$ films deposited on glass substrate with different Ag contents. 


\section{Conclusions}

The average transmittance for $\mathrm{TiO}_{2}$ films is over $94 \%$ we can use these samples as an optical window in solar cell, because that $\mathrm{TiO}_{2}$ films have average transmittance large in the wavelength range $(320-1100 \mathrm{~nm})$ and the transmittance in UV and infrared region decreases with the increase of $\mathrm{Ag}$ concentration.The optical analysis showed that the influence of Ag-content on the energy gap of $\operatorname{Ag}_{\mathrm{x}} \mathrm{Ti}_{1-\mathrm{x}} \mathrm{O}_{2}$ films is significant and found that the band gap of $\mathrm{TiO}_{2}$ could be wide anddecreases with the increase of $\mathrm{Ag}$ content. The observed shift in the absorption edge towards the red region clearly reflects the incorporation of $\mathrm{Ag}$ in the $\mathrm{TiO}_{2}$ lattice.Also optical properties of $\mathrm{TiO}_{2}$ thin films show that the films have allowed direct transition and allowed indirect transition. Increasing of the Ag contentfor all films cause a decrease in the optical band gap value and an increase in the optical constants (refractive index (n), extinction coefficient $(\mathrm{K})$, real and imaginary parts of the dielectric constant and optical conductivity $(\sigma))$.

\section{References}

[1] N. T. Nolan, D. W. Synnott, M. K. Seery, S. J. Hinder, A. V. Wassenhoven, S. C. Pillai, Effect of N-doping on the photocatalytic activity of sol-gel $\mathrm{TiO}_{2}$, Journal of Hazardous Materials, Vol. [211-212], (2011), 88-94.

[2] R. Jaiswal, N. Patel, D.C. Kothari, A. Miotello, Improved visible light photocatalytic activity of TiO $\mathrm{T}_{2}$ co-doped withVanadium and Nitrogen, Applied Catalysis B: Environmental, Vol. [126], (2012), 47-54.

[3] A. Abazarpoor, M. Halali, M. Maarefvand, H. Khatibnczhad, Application of Response Surface Methodology and Central Composite Rotatable Design for Modeling and Optimization of Sulfuric Leaching of Rutile Containing Slag and Ilmenite, Russian Journal of Non-Ferrous Metals, Vol. [54], 5, (2013), 388-397.

[4] S.H. Cheung, P. Nachimuthu, A.G. Joly, M.H. Engelhard, M.K. Bowman, S.A. Chambers, N incorporation and electronic structure

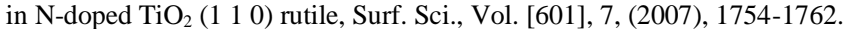

[5] HediyehKhatibnezhad, Mohammad Ali FaghihiSani and YaldaNamkhah, Effect of N-doping on the optical properties of Titanium dioxide thin film, Journal of The Australian Ceramic Society Volume 52[1], 2016, 112 - 117.

[6] [6] R. Mechiakh, F. Meriche, R. Kremer, R. Bensaha, B. Boudine, A. Boudrioua, Optical Materials 30 (2007) 645.

[7] S. Lien, D. Wuu, W. Yeh, J. Liu, Tri-layer antireflection coatings $\left(\mathrm{SiO}_{2} / \mathrm{SiO}_{2}-\mathrm{TiO}_{2} / \mathrm{TiO}_{2}\right)$ for silicon solar cells using a sol-gel technique, Solar Energy Materials \& Solar Cells, 90 (2006) 2710-2719.

[8] S. JanitabarDarzi; A. R.Mahjoub; A. Bayat, Synthesis and characterization of visible light active S-doped TiO2Nanophotocatalyst, Int. J. Nano Dimens., 7(1): 33-40, Winter 2016.

[9] Asiri A. M., Al-Amoudi M. S.,Bazaid S. A., Adam A. A., Alamry K. A., Anandan S., Enhanced visible light photodegradation of water pollutants over N-, S-doped titanium dioxide and n-titanium dioxide in the presence of inorganic anions. J. Saudi. Chem. Soc.18, (2014): 155-163.

[10] Zhao B., Mele G., Pio I., Li J., Palmisano L.,Vasapollo G., Degradation of 4-Nitrophenol (4-NP) Using Fe- TiO 2 as a Heterogeneous Photo-Fenton Catalyst. J. Hazard Mater. 176, (2010): 569-574.

[11] Hamadanian M., Reisi-Vanani A.,Majedi A., characterization and effect of calcination temperature on phase transformation and photocatalytic activity of $\mathrm{Cu}$, Scodoped $\mathrm{TiO}_{2}$ nanoparticles. Appl. Surf. Sci. 256, (2010): 1837- 1844.

[12] Zhang Z., Wang X., Long J.,Gu Q., Ding Z., Fu X., Nitrogen-doped titanium dioxide visible light photocatalyst: Spectroscopic dentification of photoactive centers. J. Catal. 276, (2010): 201-214.

[13] Janitabar-Darzi S.,Mahjoub A. R., Nilchi A., Investigation of structural, optical and photocatalytic properties of mesoporous TiO 2 thin film synthesized by sol.geltemplating technique. Physica E. 42, (2009): 176.181.

[14] P. Peerakiatkhajohn1, W. Onreabroy, C. Chawengkijwanich and S. Chiarakorn, Preparation of Visible-Light-Responsive TiO2 Doped Ag Thin Film on PET Plastic for BTEX Treatment, Journal of Sustainable Energy \& Environment 2 (2011) $125-121$.

[15] A. P. Caricatoa, M. Catalanob, G. Ciccarellac, M. Martinoa, R. Rellab, F. Romanoa, J.Spadavecchiab, A.Taurinob, T. Tunnoa, and D.Valerinia" Matrix Assisted Pulsed LaserEvaporation for $\mathrm{TiO}_{2}$ Nanoparticle Thin Film Deposition " Journal of Nanomaterials andBiostructures 1 (2005), p. 43.

[16] Sun L, Li J, Wang C, Li S, Lai Y, Chen H, Lin C, Ultrasound aided photochemical synthesis of Ag loaded TiO2 nanotube arrays to enhance photocatalytic activity, Journal of Hazardous Materials, 171 (2009) 1045-1050

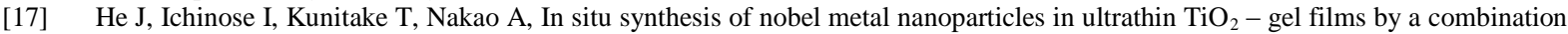
of ion-exchange and reduction processes, Langmuir 18 (2002) 10005-10010.

[18] Garcia-Serrano J, Gmez-Hernndez E, Ocampo-Fernndez M, Pal U, Effect of Ag doping on the crystallization and phase transition of $\mathrm{TiO}_{2}$ nanoparticles, Current Applied Physics 9 (2009) 1097-1105.

[19] Mohammad Reza Behforooz1, HalehKangarlou, Structural and Optical Properties of TiO $2 / \mathrm{Ag}_{\mathrm{TiO}} \mathrm{T}_{2} \mathrm{Multi}_{\mathrm{Layers}}$ J. Basic. Appl. Sci. Res., 2(10)10234-10240, 2012.

[20] L.C.Tien ,D.P.Norton, and J.D.Budai "Epitaxial growth of transparent titania films on (0001) sapphire by pulsed laser deposition " Materials Research Bulletin 36(2004),p.51. 